\title{
Process optimization of low calorie and fiber enriched 'Sandesh' using response surface methodology (RSM)
}

\author{
Himanshu Kumar Rai*, Dinesh Chandra Rai, Arvind and Saloni
}

Department of Dairy Science and Food Technology, Institute of Agricultural Sciences, Banaras Hindu University, Varanai-221005, U.P., India

\section{Article Info}

\section{Article history}

Received 4 May 2020

Revised 20 June 2020

Accepted 22 June 2020

Published online 30 June 2020

Keywords

Sorbitol

Response surface methodology

Traditional sweet

Stevia

\begin{abstract}
'Sandesh' is a most popular 'Chhana' based sweet delicacy of eastern part of India, especially West Bengal, India. A process for manufacturing a traditional sweet based on oat flour, sorbitol and Stevia as main ingredients was optimized. During the investigation, the effect of different levels of oat flour, sorbitol and Stevia was studied by employing central composite rotatable design. The best formulation was consist of $4 \%$ sorbitol, $0.25 \%$ Stevia and $15 \%$ oat flour. This formulation was found to be most suitable for preparation of low calorie and fiber enriched 'Sandesh' with predicted scores of 8.408, $8.504,8.302,8.404$ and 8.511 for body and texture, colour and appearance, flavour, sweetness and overall acceptability, respectively.
\end{abstract}

\section{Introduction}

India is the largest milk producer in the world and $50 \%$ of total produce is used by unorganised sector for manufacturing of many delicacies. In heat-acid coagulated products 'Chhana' and Paneer are the main products. 'Chhana' is extensively used for the preparation of many sweets like 'Chamcham', 'Rosogulla', 'Rasmalai', 'Sandesh', etc.

'Sandesh' is a most popular 'Chhana'-based sweet delicacy of eastern part of India, especially West Bengal, India. 'Sandesh' is heat-acid coagulated product. It is a rich source of high quality animal protein, fat, minerals and vitamins. It is a sweet product mostly produced in unorganized small-scale sectors (Bandopadhyay et al., 2007).

Oat flour is a natural and abundant source of complex carbohydrates and soluble dietary fibers which is capable of lowering the cholesterol which reduces the risk of suffering cardiovascular diseases Paul and Riar (2017). Oat flour stabilizes the glucose levels due to the progressive absorption rate of its carbohydrates, whose own glycemic index is scarce. Oats are also good for skin which is why there is addition of oatmeal to lots of skincare products. They are a good source of magnesium too so assist in energy production.

Stevia (Stevia rebaudiana) is a short and shrubby plant and natural sweetener (non-artificial) in the genus Stevia of the sunflower family (Asteraceae). Low calorie makes it a good alternative of sugar for patients, suffering from diabetes and other sedentary life related diseases (Thiyagarajan and Venkatachalam, 2015).

Corresponding author: Mr. Himanshu Kumar Rai

Department of Dairy Science and Food Technology, Institute of Agricultural Sciences, Banaras Hindu University, Varanai-221005, U.P., India

E-mail: raihimanshuias@gmail.com

Tel.: +91-9598232301

Copyright (C) 2020 Ukaaz Publications. All rights reserved.

Email: ukaaz@yahoo.com; Website: www.ukaazpublications.com
Sorbitol is a sugar alcohol, found in fruits and plants with diuretic, laxative and cathartic property. Like all sugar alcohols, it is not metabolized by bacteria in the mouth and so it does not contribute to tooth decay. It contains about one-third fewer calories than sugar and is 60 per cent as sweet. Sorbitol is less caloric than sugar $(2.4$ $\mathrm{kcal} / \mathrm{g}$ instead of $4 \mathrm{kcal} / \mathrm{g}$ ). It is popular in the production of sugar free products because it adds bulk and stiffness in the absence of sugar. It has low glycemic index.

\section{Materials and Methods}

\subsection{Collection of raw materials}

Cow milk was procured from the Dairy farm, Institute of Agricultural Sciences, BHU, Varanasi, U.P., India. Milk was standardized to $3.0 \%$ fat and $8.5 \%$ SNF using skim milk with the help of Pearson's square. Three levels of oat flour $(10 \%, 15 \%$ and $20 \%$, three levels of Stevia $(0.20 \%, 0.25 \%$ and $0.30 \%)$ and sorbitol $(2 \%, 4 \%$ and $6 \%)$ were used in the investigation (Table 1$)$. All three variables were taken according to weight of 'Chhana'. Oat flour, sorbitol and Stevia powder were procured from different sources. Central composite rotatable design (CCRD) provided 20 trials (Table 2), which were conducted to obtain a combination of selected parameters for production of the best quality low calorie and fiber enriched 'Sandesh' (Figure 1).

\subsection{Chemical characteristics of low calorie and fiber enriched} 'Sandesh'

All chemical analyses were carried out in triplicate. Moisture, fat, protein, carbohydrate and fiber contents of the product were analysed by the method given in AOAC (1990).

\subsection{Texture profile analysis (TPA)}

TPA on samples was performed by using the Texture Analyser TA.XT plus, to characterize the hardness, adhesiveness, springiness, 
cohesiveness and gumminess of 'Sandesh'. The samples of 'Sandesh' were cut into $1.5 \mathrm{~cm}^{3}$ size pieces and their temperature maintained at $25^{\circ} \mathrm{C}$ during the textural analysis.

2.4 Sensory characteristics of low calorie and fiber enriched 'Sandesh'

Sensory quality of low calorie and fiber enriched 'Sandesh' samples was judged by a panel of 10 semi-trained judges. The 'Sandesh' samples of each trial were evaluated for sensory attributes, viz., colour and appearance, flavour, sweetness, body and texture and overall acceptability based on 9-point hedonic scale.

\subsection{Statistical analysis}

Analysis of data generated during the present investigation was carried out using RSM by employing central composite rotatable design. The experimental data obtained from the design were analysed by the response surface regression procedure (Table 3).

Table 1: Three independent variables used in response surface methodology

\begin{tabular}{|l|l|l|l|l|l|l|l|l|l|}
\hline Factor & Name & Units & Type & Minimum & Maximum & Coded low & Coded high & Mean & Std. Dev. \\
\hline A & Sorbitol & $\%$ & Numeric & 0.6364 & 7.36 & $-1 \leftrightarrow 2.00$ & $+1 \leftrightarrow 6.00$ & 4.00 & 1.70 \\
B & Oat flour & $\%$ & Numeric & 6.59 & 23.41 & $-1 \leftrightarrow 10.00$ & $+1 \leftrightarrow 20.00$ & 15.00 & 4.24 \\
C & Stevia & $\%$ & Numeric & 0.1659 & 0.3341 & $-1 \leftrightarrow 0.20$ & $+1 \leftrightarrow 0.30$ & 0.2500 & 0.0424 \\
\hline
\end{tabular}

Table 2: Experimental runs and actual values of factors used in central composite rotatable design

\begin{tabular}{|c|c|c|c|c|c|c|c|c|}
\hline \multicolumn{4}{|c|}{ Factor } & \multicolumn{5}{|c|}{ Response } \\
\hline & 1 & 2 & 3 & 1 & 2 & 3 & 4 & 5 \\
\hline Run & A: Sorbitol & B:Oat flour & C:Stevia & $\begin{array}{l}\text { Body and } \\
\text { texture }\end{array}$ & $\begin{array}{l}\text { Colour and } \\
\text { appearance }\end{array}$ & Flavour & Sweetness & $\begin{array}{l}\text { Overall } \\
\text { acceptability }\end{array}$ \\
\hline & $\%$ & $\%$ & $\%$ & & & & & \\
\hline 1 & 4 & 15 & 0.25 & 8.4 & 8.5 & 8.3 & 8.4 & 8.5 \\
\hline 2 & 7.36359 & 15 & 0.25 & 7.1 & 7.2 & 7.1 & 6.9 & 7.1 \\
\hline 3 & 2 & 20 & 0.20 & 6.8 & 6.6 & 6.7 & 6.8 & 6.6 \\
\hline 4 & 6 & 10 & 0.20 & 6.7 & 6.5 & 6.6 & 6.5 & 6.5 \\
\hline 5 & 6 & 20 & 0.30 & 6.4 & 6.5 & 6.3 & 6.4 & 6.5 \\
\hline 6 & 2 & 10 & 0.30 & 6.6 & 7.1 & 6.9 & 6.8 & 6.9 \\
\hline 7 & 4 & 15 & 0.25 & 8.4 & 8.5 & 8.3 & 8.4 & 8.5 \\
\hline 8 & 6 & 10 & 0.30 & 6.6 & 6.7 & 6.8 & 6.9 & 6.7 \\
\hline 9 & 4 & 15 & 0.16591 & 7.6 & 7.2 & 7.1 & 7.1 & 7.4 \\
\hline 10 & 4 & 15 & 0.33409 & 7.8 & 7.1 & 7.2 & 7.3 & 7.2 \\
\hline 11 & 4 & 6.59104 & 0.25 & 6.4 & 6.8 & 6.7 & 6.5 & 6.7 \\
\hline 12 & 4 & 23.409 & 0.25 & 6.3 & 6.5 & 6.4 & 6.6 & 6.8 \\
\hline 13 & 6 & 20 & 0.20 & 7.4 & 7.5 & 7.3 & 7.4 & 7.2 \\
\hline 14 & 4 & 15 & 0.25 & 8.4 & 8.5 & 8.3 & 8.4 & 8.5 \\
\hline 15 & 2 & 10 & 0.20 & 6.6 & 6.5 & 6.3 & 6.4 & 6.3 \\
\hline 16 & 4 & 15 & 0.25 & 8.4 & 8.5 & 8.3 & 8.4 & 8.5 \\
\hline 17 & 4 & 15 & 0.25 & 8.4 & 8.5 & 8.3 & 8.4 & 8.5 \\
\hline 18 & 2 & 20 & 0.30 & 7.2 & 7.2 & 7.1 & 7.1 & 7.2 \\
\hline 19 & 4 & 15 & 0.25 & 8.4 & 8.5 & 8.3 & 8.4 & 8.5 \\
\hline 20 & 0.636414 & 15 & 0.25 & 7.1 & 7.1 & 6.9 & 6.9 & 7.1 \\
\hline
\end{tabular}

Table 3: $\mathrm{p}$ and $\mathrm{R}^{2}$ value of regression equation of suggested model for sensory characteristics

\begin{tabular}{|l|l|l|l|l|l|}
\hline Terms & $\begin{array}{l}\text { Colour and } \\
\text { appearance }\end{array}$ & Flavour & Sweetness & Body and texture & $\begin{array}{l}\text { Overall } \\
\text { acceptability }\end{array}$ \\
\hline Model & Quadratic & Quadratic & Quadratic & Quadratic & Quadratic \\
\hline F VALUE & 35.36 & 43.05 & 49.44 & 25.80 & 36.40 \\
P value & $<.0001$ & 0.0001 & $<0.0001$ & $<0.0001$ & $<0.0001$ \\
MEAN & 7.38 & 0.26 & 7.30 & 7.35 & 7.36 \\
Standard Deviation & 0.1942 & 2.26 & 0.1605 & 0.2258 & 0.3301 \\
C.V. \% & 2.63 & 0.9748 & 0.20 & 3.07 & 2.62 \\
$\mathrm{R}^{2}$ & 0.9695 & 0.9522 & 0.9582 & 0.9587 & 0.9704 \\
Adjusted R & 0.9421 & 0.7905 & 0.8047 & 0.9215 & 0.9437 \\
Predicted R & 0.7458 & 0.2689 & 0.2576 & 0.7517 & 0.7630 \\
Lack of fit & 0.3771 & & 0.5100 & 0.3728 \\
\hline
\end{tabular}




\section{Results}

3.1 Proximate composition of low calorie and fiber enriched 'Sandesh'

The chemical composition of low calorie and fiber enriched 'Sandesh' prepared using 4\% sorbitol, $0.25 \%$ Stevia and $15 \%$ oat flour was determined and the results are presented in Table 4.

Table 4: Proximate chemical composition of low calorie and fiber enriched 'Sandesh'

\begin{tabular}{|l|r|}
\hline Constituent & Composition (\%) Mean \pm SD \\
\hline Moisture & $30.74 \pm 0.41$ \\
Fat & $19.30 \pm 0.13$ \\
Total protein & $21.40 \pm 0.20$ \\
Total ash & $1.87 \pm 0.08$ \\
Fiber content & $0.92 \pm 0.06$ \\
Carbohydrate & $25.77 \pm 0.21$ \\
Acidity & $1.30 \pm 0.06$ \\
\hline
\end{tabular}

\subsection{Textural properties of low calorie and fiber enriched 'Sandesh'}

The textural property of low calorie and fiber enriched 'Sandesh' prepared using $4 \%$ sorbitol, $0.25 \%$ Stevia and $15 \%$ oat flour was determined and the results are presented in Table 5.

Table 5: Textural properties of Optimized 'Sandesh'

\begin{tabular}{|l|c|}
\hline Constituent & Value $($ Mean \pm SD) \\
\hline Hardness $(\mathrm{g})$ & $3408 \pm 0.11$ \\
Adhesiveness (g.sec) & $15.60 \pm 0.09$ \\
Springiness (mm) & $0.25 \pm 0.01$ \\
Cohesiveness & $0.052 \pm 0.03$ \\
Gumminess (g) & $177.21 \pm 0.89$ \\
\hline
\end{tabular}

\subsection{Effect of physical factors on sensory properties of optimized product}

\subsubsection{Effect on body and texture}

The body and texture score for low-calorie and fiber enriched 'Sandesh' was 6.3 to 8.4 (Table 2). The maximum score obtained when the levels of sorbitol, oat flour and Stevia were $4.00 \%, 15.00 \%$ and $0.25 \%$, respectively. Figure 2 (a) shows the interactive effect of sorbitol and oat flour on body and texture score. It can be clearly deduced from 3D surface and that the increase in sorbitol and oat flour, increased the body and texture score. However, further increase in these two variables decreased the body and texture score. The maximum body and texture score was obtained when the level of sorbitol and oat flour was held at $4 \%$ and $15 \%$, respectively. Figure 2 (b) shows the interactive effect of sorbitol and Stevia on the body and texture score. Figure 2 (b) brings out the fact that, increase in level of sorbitol and Stevia increased the body and texture score up to $4 \%$ and $0.25 \%$, respectively. However, further increase in the concentration of sorbitol and Stevia had negative effect on the body and texture score. Figure 2 (c) shows the interactive effect of oat flour and Stevia on body and texture. Initially, there was an increase in body and texture score when the concentration of oat flour and Stevia increased, but further increase in the concentration of both the variables resulted in the decrease of body and texture score. The maximum body and texture score obtained was at $15 \%$ oat flour and $0.25 \%$ Stevia concentration. The quadratic model for body and texture was found to be significant at $(p<0.0001)$. The coefficient of determination $\left(\mathrm{R}^{2}\right)$ was then 0.9587 . The "Pred R-Squared" of 0.7517 is in a reasonable agreement with the "Adj R-Squared" of 0.9215 . Hence, the model could navigate the design space.

\subsubsection{Effect on colour and appearance}

The colour and appearance score for low-calorie and fiber enriched 'Sandesh' varied from 6.5 to 8.5 (Table 2). The maximum score was procured for the experiment when the levels of sorbitol, oat flour and Stevia were $4 \%, 15 \%$ and $0.25 \%$, respectively. Figure 3 (a), shows the interactive effect of sorbitol and oat flour on the colour and appearance score. It shows that the level of sorbitol and oat flour is built up, there is an increase in the colour and appearance score up to $4 \%$ and $15 \%$ levels, respectively, but further escalation in the concentration of sorbitol and oat flour resulted in the decrease of colour and appearance score. Figure 3 (b) shows the interactive effect of sorbitol and Stevia on colour and appearance. It shows that when the level of sorbitol and Stevia is augmented, colour and appearance score also showed an increase. The interaction of sorbitol and Stevia had positive effect on the colour and appearance score up to $4 \%$ and $0.25 \%$ levels, respectively. Further, an increase in the level of sorbitol and Stevia results in decrease of colour and appearance score. Figure 3 (c) shows the effect of the combination of two variables of oat flour and Stevia, on colour and appearance score. Figure 3 (c) shows similar trend as in Figure 2 (b). The colour and appearance score started to decrease when the level of oat flour and Stevia was increased over $15 \%$ and $0.25 \%$, respectively. The quadratic model for body and texture was found to be significant at $(p<0.0001)$. The coefficient of determination $\left(\mathrm{R}^{2}\right)$ was 0.9695 . The "Pred R-Squared" of 0.7458 is in reasonable agreement with the "Adj R-Squared" of 0.9421 . Hence, the model could navigate the design space.

\subsubsection{Effect on flavour}

The flavour score for low-calorie and fiber enriched 'Sandesh' varied from 6.3 to 8.3 (Table 2). The maximum score was obtained for experiment when the levels of sorbitol, oat flour and Stevia were $4 \%, 15 \%$ and $0.25 \%$, respectively. Figure 4 (a), 4 (b) and 4 (c) show the interactive effect sorbitol-oat flour, sorbitol-Stevia and oat flourStevia, respectively on the flavour score. In Figure 4 (a), maximum flavour score was observed when the concentrations of sorbitol and oat flour were $4 \%$ and $15 \%$, respectively. Similarly, in Figure 4 (b) maximum score of flavour was observed when the concentration of sorbitol and Stevia was kept at $4 \%$ and $0.25 \%$, respectively and in Figure 4 (c) maximum flavour score was observed when concentration of sorbitol and oat flour was kept at $4 \%$ and $15 \%$. In Figure 4 (a), flavour score increases with increase in concentration of sorbitol and oat flour up to $4 \%$ and $15 \%$. However, further escalation in two variables decreases the flavour score. In Figure 4 (b), flavour score increases with increase in concentration of sorbitol 
and Stevia up to $4 \%$ and $0.25 \%$. However, further escalation in two variables decreases the flavour score. In Figure 4 (c), combination of oat flour and Stevia had a positive impact on flavour score up to $15 \%$ and $0.25 \%$ and decreases with further increase. The quadratic model for body and texture was found to be significant at $(p<0.0001)$. The coefficient of determination $\left(\mathrm{R}^{2}\right)$ was 0.9748 . The "Pred R-Squared" of 0.7905 is in reasonable agreement with the "Adj R-Squared" of 0.9522. Hence, the model could navigate the design space.

\subsubsection{Effect on sweetness}

The sweetness score for low-calorie and fiber enriched 'Sandesh' varied from 6.4 to 8.4 (Table 2). The maximum score was obtained for experiment when the levels of sorbitol, oat flour and Stevia were $4 \%, 15 \%$ and $0.25 \%$, respectively. Figure 5 (a), 5 (b) and 5 (c) show the interactive effect sorbitol-oat flour, sorbitol-Stevia and oat flour-Stevia, respectively on sweetness score. In Figure 5 (a), the score of sweetness increases with the escalation in sorbitol and oat flour concentration up to $4 \%$ and $15 \%$, and then starts decreasing with further increase of sorbitol and oat flour. In Figure 5 (b), the sweetness score increases with increase in concentration of sorbitol and Stevia up to $4 \%$ and $0.25 \%$, respectively. However, any further increase in the two variables decreases sweetness score. In Figure 5 (c), the combination of oat flour and Stevia had a positive impact on sweetness score up to $15 \%$ and $0.25 \%$, but further increase in the concentration of oat flour and Stevia lessened the sweetness score. The quadratic model for body and texture was found to be significant at $(p<0.0001)$. The coefficient of determination $\left(\mathrm{R}^{2}\right)$ was 0.9780 . The "Pred R-Squared" of 0.8047 is in reasonable agreement with the "Adj R-Squared" of 0.9582. Hence, the model could navigate the design space.

\subsubsection{Effect on overall acceptability}

The overall acceptability score for low-calorie and fiber enriched "Sandesh" 'varied from 6.3 to 8.5 (Table 2). The maximum score was obtained for the experiment when the levels of sorbitol, oat flour and Stevia were 4\%, $15 \%$ and $0.25 \%$. Figure 6 (a), 6 (b) and 6 (c) show the interactive effect sorbitol-oat flour, sorbitol-Stevia and oat flour-Stevia, respectively on overall acceptability score. In Figure 6 (a), the overall acceptability score escalated with the increase in sorbitol and oat flour concentration up to $4 \%$ and $15 \%$, respectively. However, any further rise of sorbitol and oat flour concentration reduced the overall acceptability score. In Figure 6 (b), the overall acceptability score rises with the respective increase in concentration of sorbitol and Stevia up to $4 \%$ and $0.25 \%$. However, further increase in two variables contracted the overall acceptability score. In Figure 6 (c), combination of oat flour and Stevia had a positive impact on overall acceptability score up to $15 \%$ and $0.25 \%$ level, respectively, but further heightening in the concentration of oat flour and Stevia decreased the overall acceptability score. The quadratic model for body and texture was found to be significant at $(7<0.0001)$. The coefficient of determination $\left(\mathrm{R}^{2}\right)$ was 0.9704 . The "Pred R-Squared" of 0.7630 is in reasonable agreement with the "Adj R-Squared" of 0.9437 . Hence, the model could navigate the design space.
Preparation of Low calorie and fiber enriched 'Sandesh':

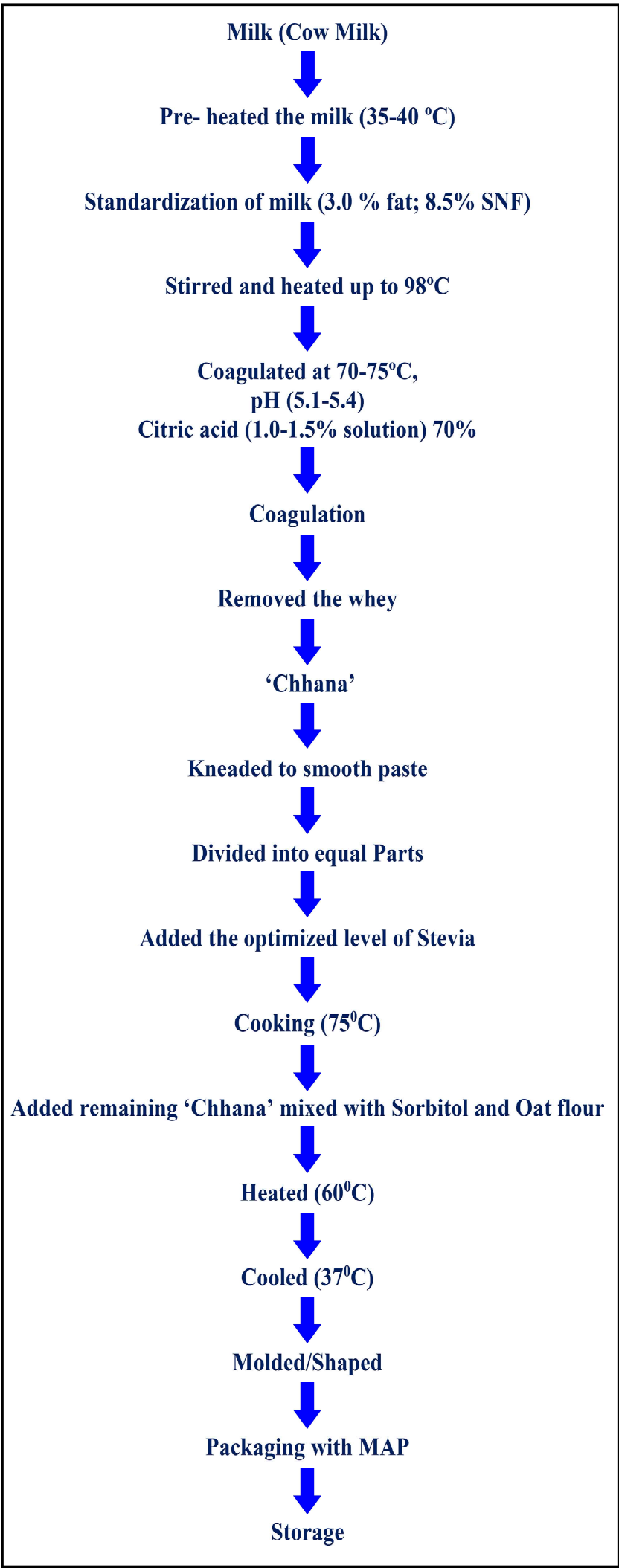

Figure 1: Flow diagram of low calorie and fiber enriched "Sandesh" preparation. 


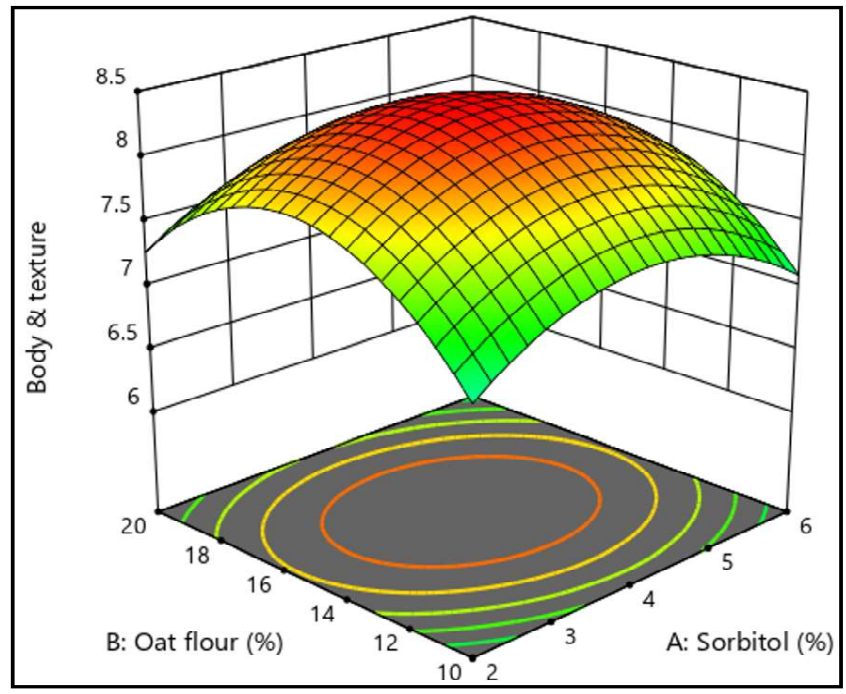

Figure 2(a): Effect of oat flour and sorbitol on body and texture.

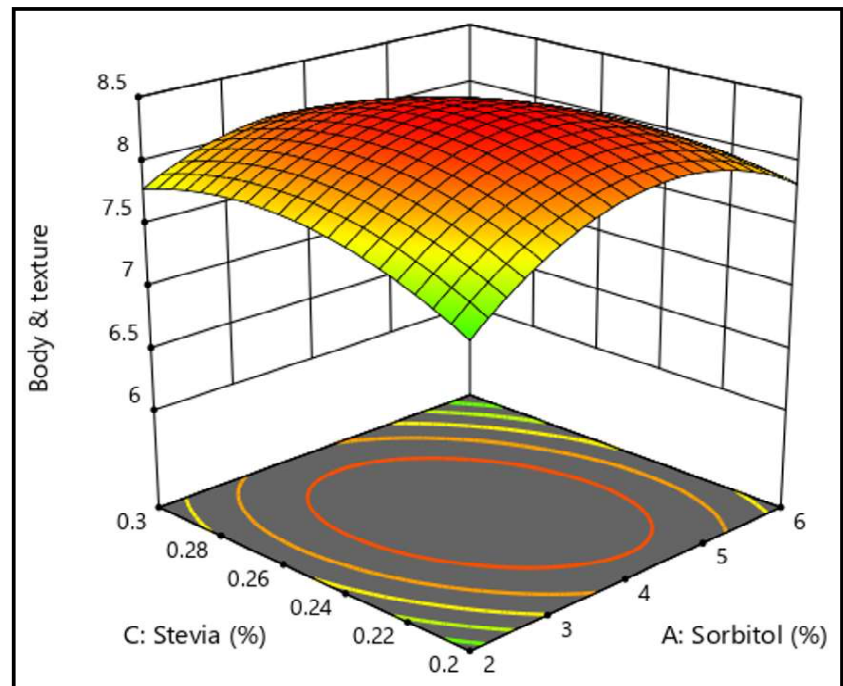

Figure 2(b): Effect of Stevia and sorbitol on body and texture.

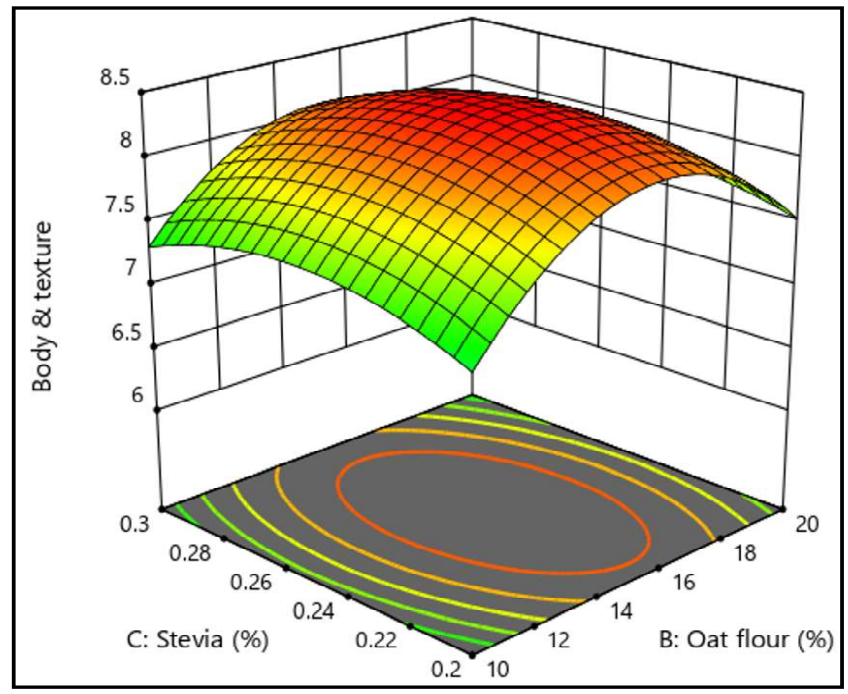

Figure 2(c): Effect of oat flour and Stevia on body and texture.

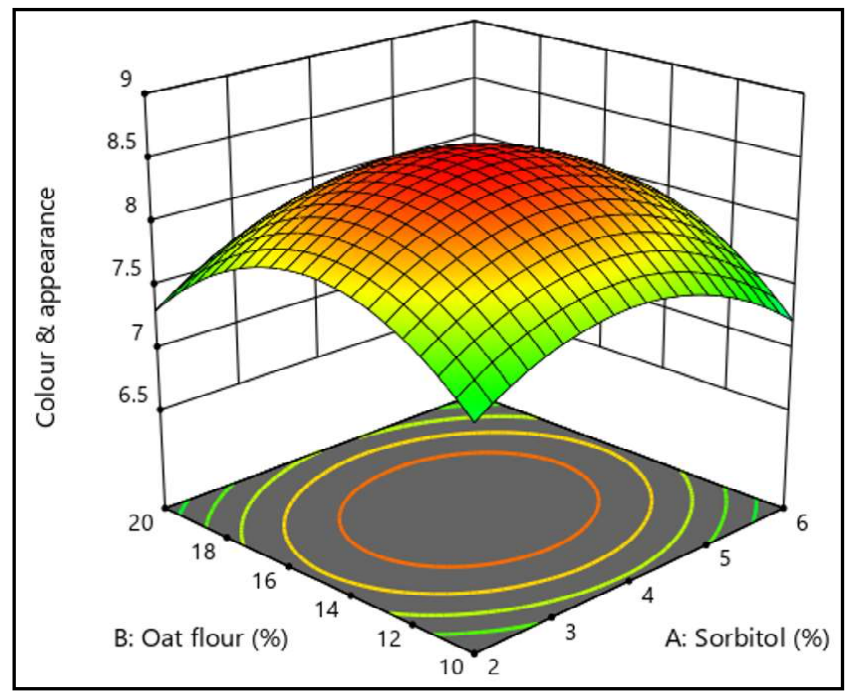

Figure 3(a): Effect of oat flour and sorbitol on colour and appearance.

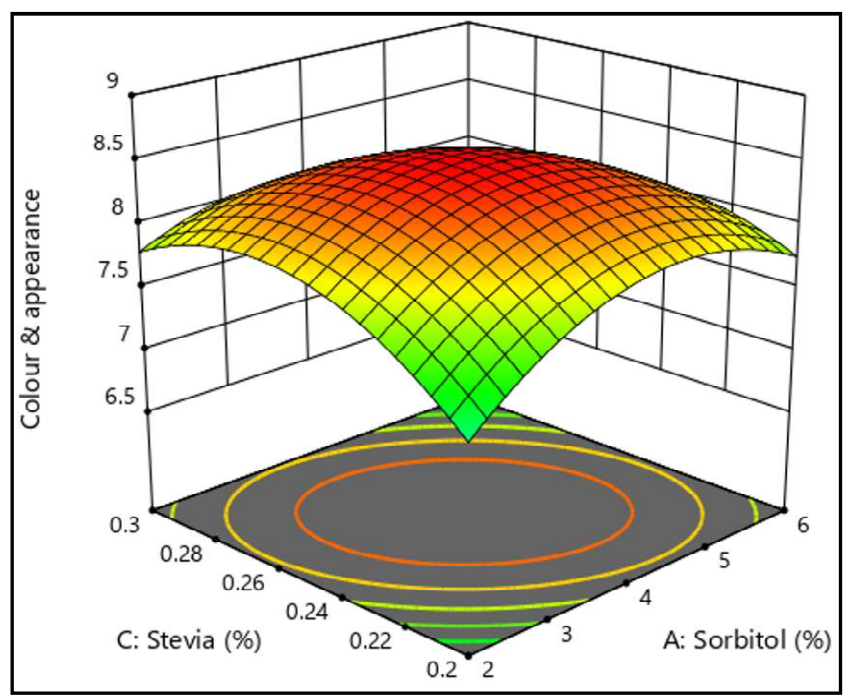

Figure 3(b): Effect of Stevia and sorbitol on colour and appearance.

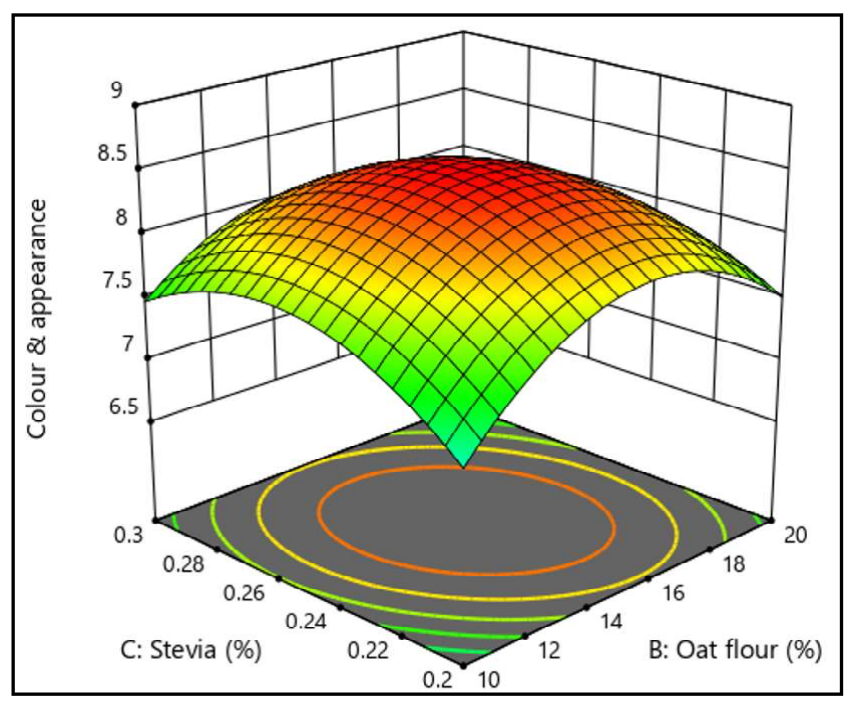

Figure 3(c): Effect of oat flour and Stevia on colour and appearance. 


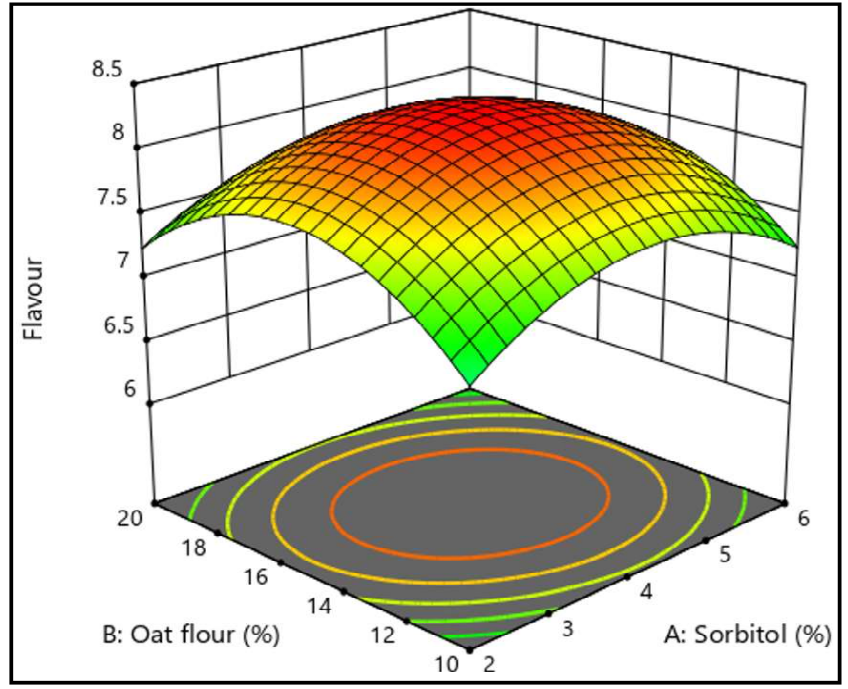

Figure 4(a): Effect of oat flour and sorbitol on flavour.

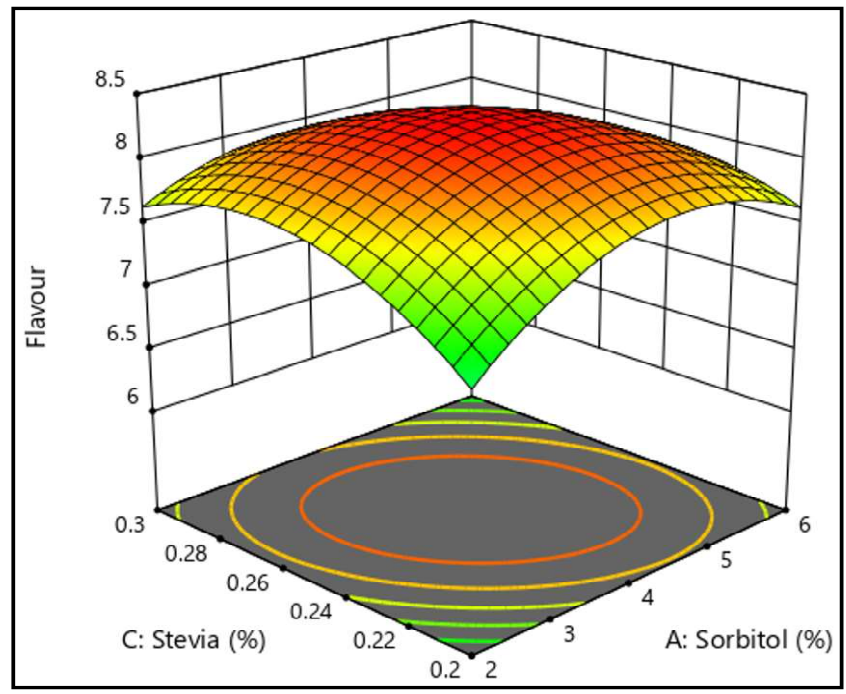

Figure 4(b): Effect of Stevia and sorbitol on flavour.

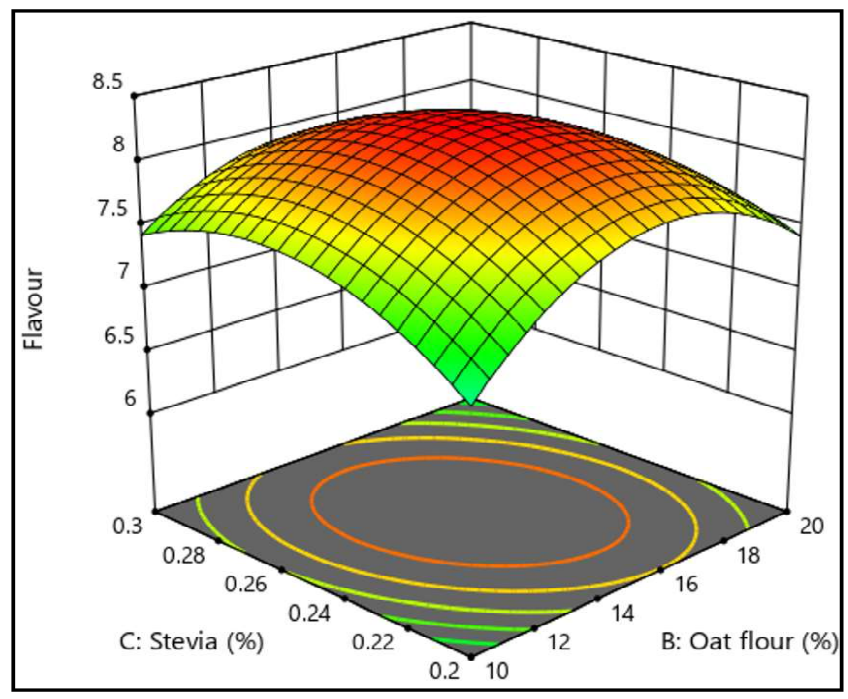

Figure 4(c): Effect of oat flour and Stevia on flavour.

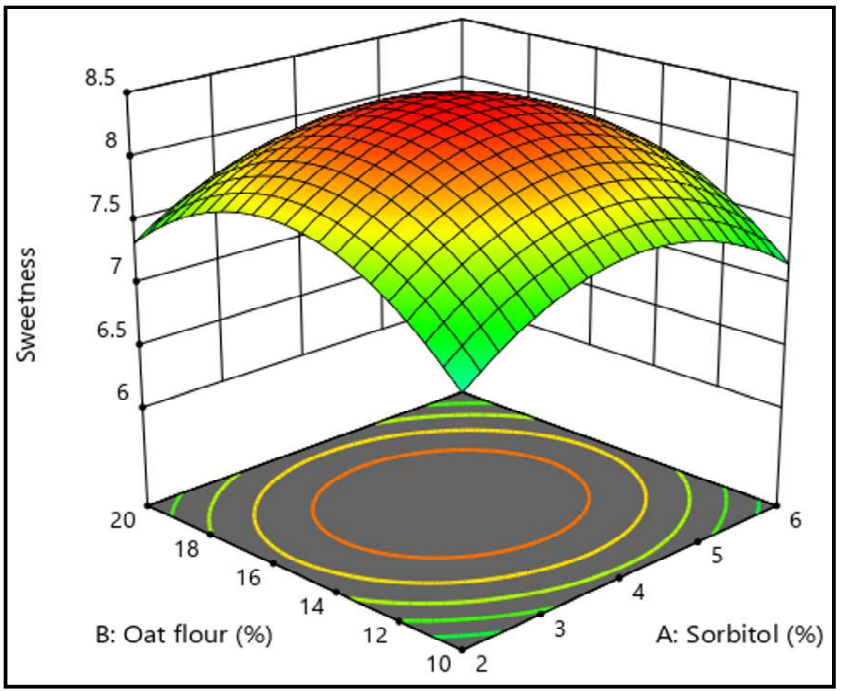

Figure 5(a): Effect of oat flour and sorbitol on sweetness.

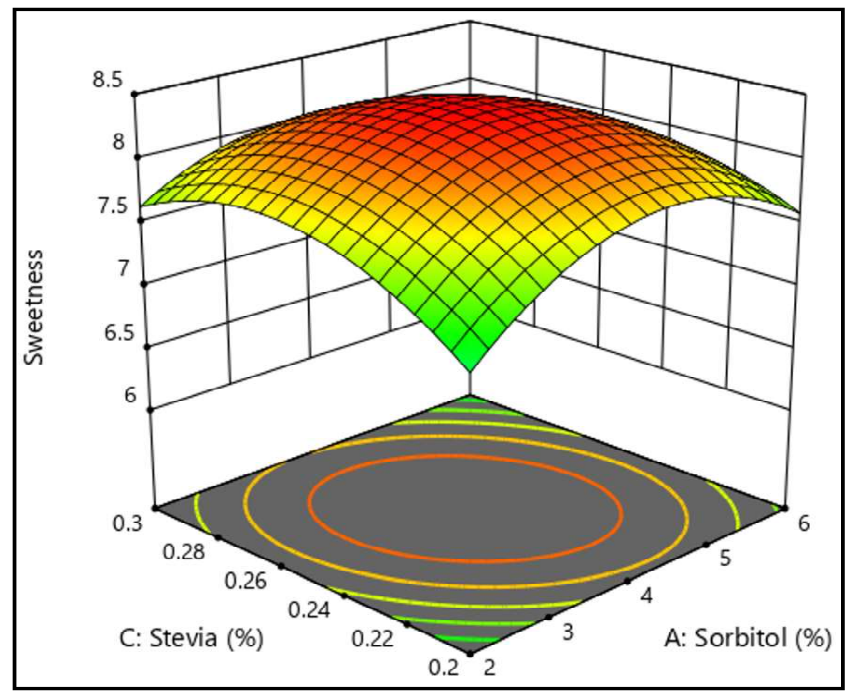

Figure 5(b): Effect of Stevia and sorbitol on sweetness.

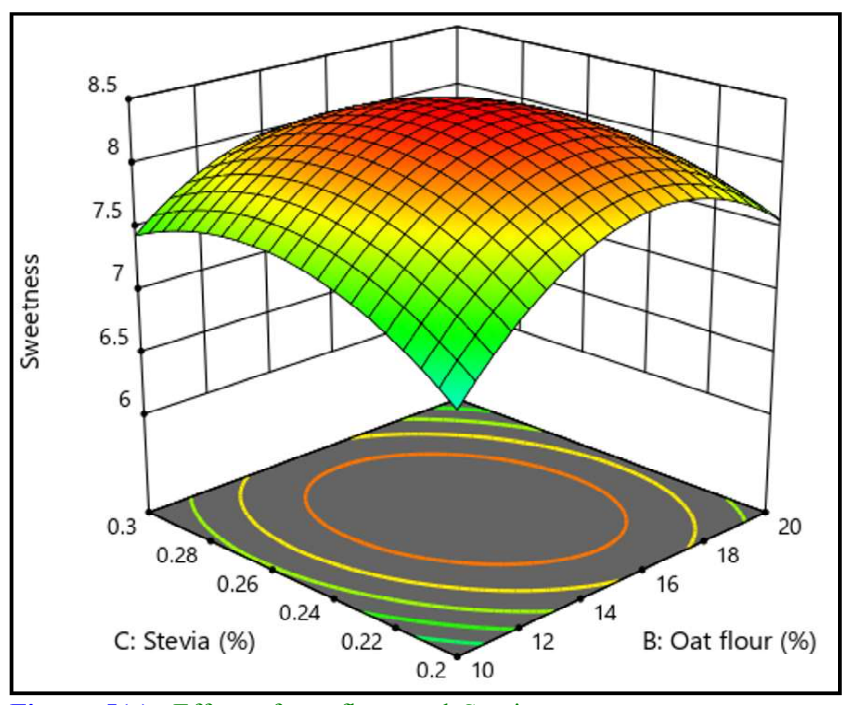

Figure 5(c): Effect of oat flour and Stevia on sweetness. 


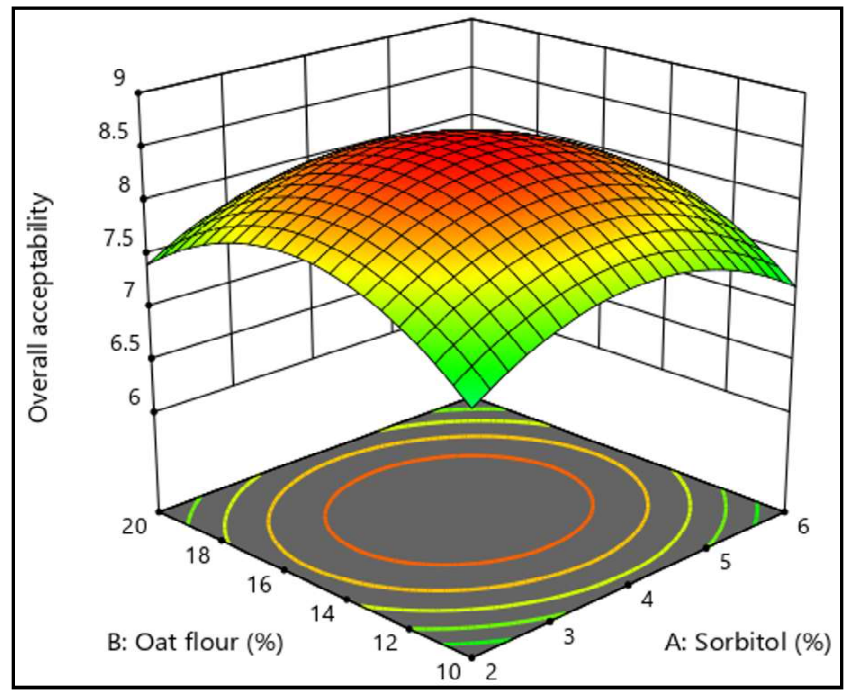

Figure 6(a): Effect of oat flour and sorbitol on overall acceptability.

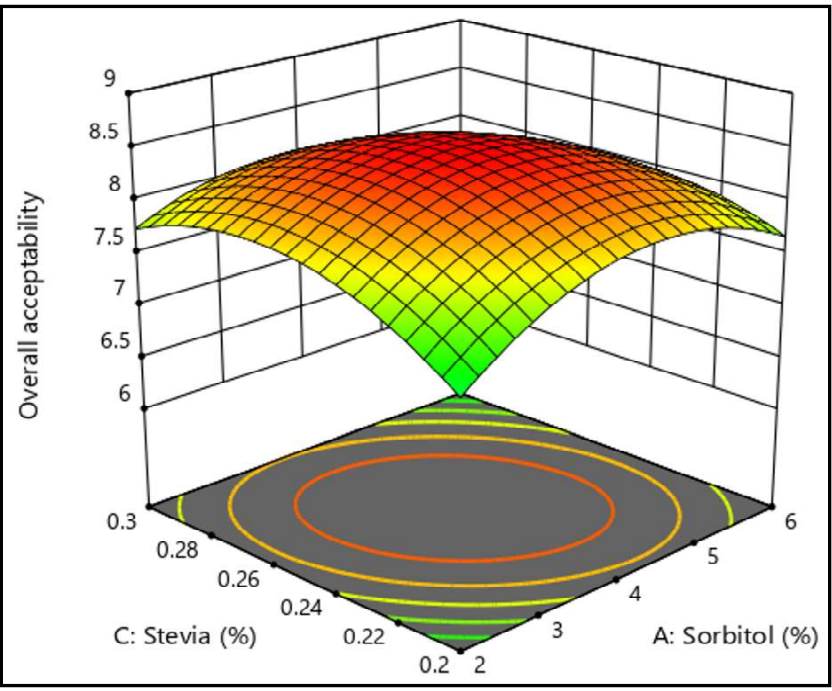

Figure 6(b): Effect of Stevia and sorbitol on sweetness.

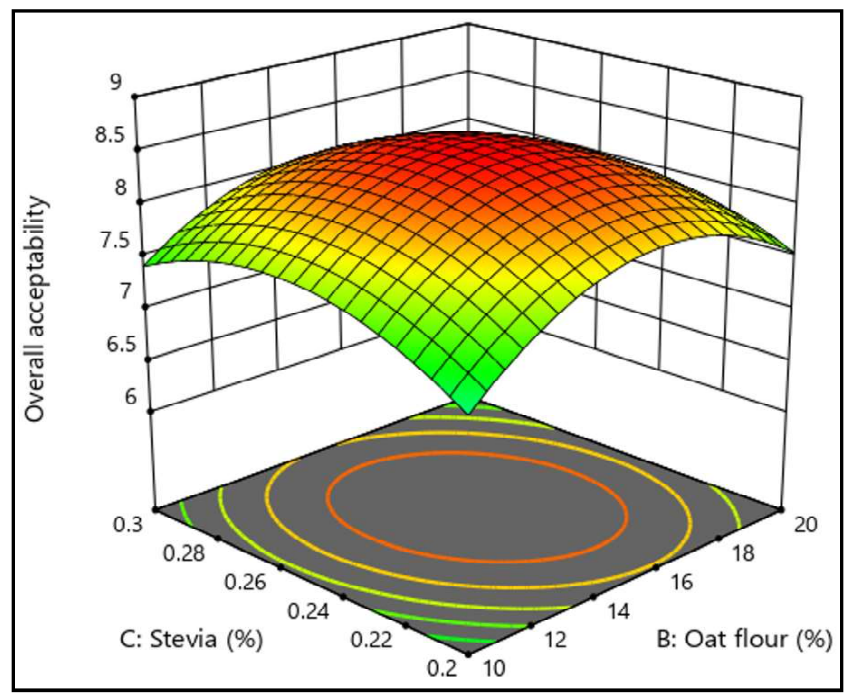

Figure 6(c): Effect of Stevia and oat flour on overall acceptability.

\section{Discussion}

An attempt was made to manufacture low calorie and fiber enriched 'Sandesh' and the level of sorbitol, oat flour and Stevia optimized on the basis of sensory score were $4 \%, 15 \%$ and $0.25 \%$, respectively. The optimization was done strictly on the basis of sensory score. Every figure shows the interactive effect of two variables on sensory properties (body and texture, colour and appearance, flavour, sweetness and overall acceptability) and value of the third variable was kept constant as actual value. All the variables show significant effect on sensory properties. Although, sensory properties can be controlled by precise monitoring all the three variables (Table 6).

The body and texture score initially increased and then decreased gradually. This may be due to fact that, artificial sweeteners alone cannot provide bulk of sugar and increased concentration of oat flour which resulted in decrease of cohesive nature of optimized 'Sandesh'. Similar findings were observed by Jain and Rai (2018) when there was increase in body and texture score with increase in Stevia concentration up to certain level then decreases when there was further increase in Stevia concentration.

Effect of different variables on flavour score was significant. Flavour score initially increased with increased concentration of different variables but further increase in their concentration, decreases the flavour score. Similar findings were observed by Kaur and Goswami (2019) when there was increase in flavour score of 'Rasogulla' with the increase in Stevia concentration up to certain level then decreases when there was further increase in Stevia concentration.

The changes observed in colour and appearance score with varied concentrations of different variables was may be due to colour imparted by increased concentration of oat flour. Similar results were observed by Majoobi et al. (2016) and Aravind et al. (2018). They studied the impact of increased concentration of whole oat flour on fresh and stored part baked bread decreases the colour score.

Sweetness is basic taste most commonly perceived when eating food rich in sugar. Sweet tastes are regarded as pleasurable experience, except perhaps in excess. The decrease in sweetness score after a certain level is may be due to lower taste profile of Stevia which produces aftertaste. Similar result was reported by Alizadeh et al. (2014) where they studied that the complete replacement of sugar with Stevia reduces the score of sweetness.

Acceptability is the distinctiveness of a food being subject to acceptance for some point. A food is acceptable if it is adequate to serve the purpose for which it is provided. Overall acceptability score initially increased with increased concentration of different variables but further increase in the concentration of variables resulted in decrease of overall acceptability score. Similar finding was observed by Bhise and Kaur (2014) and Singh et al. (2019) when there was increase in overall acceptability score with the increase in sorbitol concentration up to $4 \%$ then decreases when there was further increase in sorbitol concentration. 
Table 6: Predicted score of the suggested formulation Low calorie and fiber enriched 'Sandesh' by Design Expert version 12

\begin{tabular}{|c|c|c|c|c|c|c|c|c|c|c|}
\hline S.N. & $\begin{array}{l}\text { Sorbitol } \\
\%\end{array}$ & $\begin{array}{l}\text { Oat flour } \\
\%\end{array}$ & $\begin{array}{l}\text { Stevia } \\
\%\end{array}$ & $\begin{array}{l}\text { Body and } \\
\text { texture }\end{array}$ & $\begin{array}{l}\text { Colour and } \\
\text { appearance }\end{array}$ & Flavour & Sweetness & OA A & Desirability & \\
\hline 1. & 4.000 & 15.000 & 0.250 & 8.408 & 8.504 & 8.302 & 8.404 & 8.511 & 0.932 & Selected \\
\hline 2 . & 4.008 & 15.176 & 0.250 & 8.408 & 8.503 & 8.302 & 8.403 & 8.403 & 8.510 & 0.931 \\
\hline 3. & 4.103 & 15.147 & 0.251 & 8.405 & 8.501 & 8.302 & 8.401 & 8.401 & 8.508 & 0.930 \\
\hline 4. & 4.030 & 15.159 & 0.250 & 8.407 & 8.503 & 8.302 & 8.402 & 8.402 & 8.509 & 0.930 \\
\hline 5. & 4.040 & 15.229 & 0.252 & 8.406 & 8.501 & 8.302 & 8.403 & 8.403 & 8.510 & 0.928 \\
\hline 6. & 3.951 & 15.223 & 0.251 & 8.408 & 8.502 & 8.301 & 8.403 & 8.403 & 8.510 & 0.923 \\
\hline 7. & 4.068 & 15.298 & 0.249 & 8.408 & 8.501 & 8.301 & 8.402 & 8.402 & 8.509 & 0.923 \\
\hline 8. & 4.051 & 15.247 & 0.252 & 8.406 & 8.502 & 8.302 & 8.403 & 8.403 & 8.510 & 0.918 \\
\hline 9. & 3.975 & 15.299 & 0.250 & 8.408 & 8.502 & 8.301 & 8.403 & 8.403 & 8.510 & 0.918 \\
\hline 10. & 3.993 & 15.139 & 0.253 & 8.405 & 8.502 & 8.302 & 8.402 & 8.402 & 8.509 & 0.916 \\
\hline
\end{tabular}

\section{Conclusion}

Optimization of levels of sorbitol, oat flour and Stevia for manufacturing of low calorie and fiber enriched 'Sandesh' is predicted based on score of sensory quality using RSM. Out of 10 suggested formulations, the formulation No. 1 had better sensory score than all other formulations and the desirability was 0.932 , which is highest amongst all. Hence, the level of sorbitol, oat flour and Stevia optimized on the basis of sensory score were $4 \%, 15 \%$ and $0.25 \%$, respectively. From the above results, it could be concluded that low calorie and fiber enriched 'Sandesh' can be manufactured to promote value addition, export promotion and product diversification and it may has therapeutic value for the health conscious people especially for those suffering from diabetes, obesity, etc.

\section{Conflict of interest}

The authors declare that there are no conflicts of interest in the course of conducting the research. All the authors had final decision regarding the manuscript and decision to submit the findings for publication.

\section{References}

Alizadeh, M.; Azizi-Lalabadi, M. and Kheirouri, S. (2014). Impact of using Stevia on physicochemical, sensory, rheology and glycemic index of soft ice cream. Food and Nutrition Sciences, 5(4):390-396.

AOAC (1990). Official methods of analysis, association of official analytical chemists the association: Arlington: VA, Vol. II, 15th ed. Sec.985.29.

Arvind; Singh, R.P. and Pandhi, S. (2018). Process optimization for development of low-calorie milk cake. Indian J. Dairy Sci., 72(2): 138-147.
Bandyopadhyay, M.; Chakraborty, R., and Raychaudhuri, U. (2007). A process for preparing a natural antioxidant enriched dairy product (Sandesh). LWT-Food Science and Technology, 40(5):842-851.

Bhise, S. and Kaur, A. (2014). Baking quality, sensory properties and shelf life of bread with polyols. J. Food Sci. Technology, 51(9):2054-2061.

Jain, V.K. and Rai, D.C. (2018). Sensory acceptability of reduced fat, low calorie andprotein rich ice cream and its production cost estimation. The Pharma Innovation Journal, 7(10):264-268

Kaur, G. and Goswami, T.K. (2019). Effect of Stevia level on chemical, microbiological, and sensory properties of dairy dessert (Rasgulla) at different storage periods and temperatures. Journal of Food Processing and Preservation, https://doi.org/10.1111/jfpp.14293.

Majzoobi, M.; Jalali, A.R. and Farahnaky, A. (2016). Impact of whole oat flour on dough properties and quality of fresh and stored part baked bread. Journal of Food Quality, https://doi.org/10.1111/ jfq. 12237

Paul, K. and Riar, C. S. (2017). Development and characterization of dietary fiber and natural antioxidant supplemented Chhana based sweet dairy product 'Sandesh'. Asian Journal of Dairy and Food Research, 36(1):9-15.

Singh, T. P.; Chauhan, G.; Mendiratta, S. K.; Agrawal, R. K., and Arora, S. (2019). Optimization of ingredients for preparation of low calorie fiber enriched chhana balls-Sandesh like product. Journal of Food Science and Technology, 56(6):3043-3054.

Thiyagarajan, M. and Venkatachalam, P. (2015). Assessment of genetic and biochemical diversity of Stevia rebaudiana Bertoni by DNA fingerprinting and HPLC analysis. Ann. Phytomed. 4(1):79-85.

Citation: Himanshu Kumar Rai, Dinesh Chandra Rai, Arvind and Saloni (2020). Process optimization of low calorie and fiber enriched 'Sandesh' using response surface methodology (RSM). Ann. Phytomed., 9(1):229-236. http://dx.doi.org/ 10.21276/ap.2020.9.1.31 